\title{
Dual-Component Synaptic Potentials in the Lamprey Mediated by Excitatory Amino Acid Receptors
}

\author{
N. Dale ${ }^{1}$ and S. Grillner \\ Department of Physiology III, Karolinska Institute, 11344 Stockholm, Sweden
}

The synaptic mechanisms underlying amino acid-mediated excitation in the lamprey spinal cord have been investigated. Fine stimulating electrodes were used to stimulate single axons in the spinal cord and evoke unitary EPSPs in lamprey motoneurons and one type of premotor interneuron, the $\mathrm{CC}$ interncuron. Three types of EPSP, distinguished by their time course and sensitivity to amino acid antagonists, were seen. Fast EPSPs had a fast rise time (mean, 6.5 msec) and a short half-decay time (mean, $22.5 \mathrm{msec}$ ). Slow EPSPs lasted at least $200 \mathrm{msec}$, had a slow rise time (mean, $28 \mathrm{msec}$ ), and a long half-decay time (mean, 109 msec). The third type of unitary potential, called "mixed" EPSP, also lasted at least $200 \mathrm{msec}$, had a fast rise time (mean, $12 \mathrm{msec}$ ), and a long half-decay time (mean, $105 \mathrm{msec}$ ). Lamprey neurons were found to possess 3 types of excitatory amino acid receptor: $N$-methyl-D-aspartate (NMDA), kainate, and quisqualate receptors. 2-Amino-5-phosphonovaleric acid (APV) or $\mathbf{M g}^{2+}$ blocked the depolarizations caused by $\boldsymbol{N}$-methyl-D,Laspartate (NMA) but not those of kainate or quisqualate. Cis-2, 3-piperidine dicarboxylic acid (PDA) blocked the depolarizations caused by NMA and kainate but not those of quisqualate. Fast EPSPs were unaffected by the bath application of APV or $\mathrm{Mg}^{2+}$ but were greatly reduced by PDA, suggesting that these EPSPs were mediated by non-NMDA, possibly kainate receptors. Both APV and $\mathrm{Mg}^{2+}$ blocked the slow EPSPs, suggesting that they were mediated by NMDA receptors. APV and $\mathrm{Mg}^{2+}$ revealed the dual-component nature of the mixed EPSPs by selectively blocking a slow component (presumably mediated by NMDA receptors) and exposing a fast component that was very similar in shape to the fast EPSP. PDA blocked both components of the mixed EPSPs suggesting that the fast component was mediated by kainate receptors. We propose that presynaptic axons, perhaps including those of propriospinal neurons, can release an amino acid transmitter that can activate either kainate receptors to produce fast EPSPs, NMDA receptors to produce slow EPSPs or both kainate and NMDA receptors to produce dual-component, mixed EPSPs at a single physiological synapse.

Excitatory amino acid neurotransmitters, often assumed to be glutamate and/or aspartate, are thought to play a major role in mediating the excitation of neurons in many parts of the vertebrate nervous system, including the spinal cord (Dale and Roberts, 1984; Davies and Watkins, 1981, 1983; Davies et al., 1980), the hippocampus (Collingridge et al., 1983a, b; Crunelli

\footnotetext{
Received Jan. 7, 1986; revised Mar. 14, 1986; accepted Mar. 17, 1986.

We thank Dr. M. Armstrong-James for the generous gift of carbon fibers, $H$ Axegren for technical assistance and help with the illustrations, A. Vorwerk for help with typing, and the S.E.R.C. for financial support (N.D.) and the Swedish Medical Research Council (Project No. 3026).

${ }^{1}$ Correspondence should be addressed to Dr. N. Dale, Center for Neurobiology and Behavior, Columbia University, 722 West 168th Street, New York, NY 10032.

Copyright (C) 1986 Society for Neuroscience $0270-6474 / 86 / 092653-09 \$ 02.00 / 0$
}

et al., 1982), the caudate nucleus (Herrling et al., 1983), the cortex (Thomson and Lodge, 1985), and the retina (e.g., Slaughter and Miller, 1983). The endogenous transmitter, whose identity remains unknown, can activate at least 3 sorts of receptor, named $N$-methyl-D-aspartatc (NMDA), kainate, and quisqualate receptors after their most potent and selective agonists (McLennan, 1983; Watkins and Evans, 1981). In the lamprey, swimming can be initiated by the bath application of certain amino acids (Brodin et al., 1985; Grillner et al., 1981; Poon, 1980 ) that activate NMDA and/or kainate receptors (Brodin et al., 1985). NMDA receptors, in particular, may play an important role in the generation of swimming, since activation of these receptors can lead to pacemaker-like activity in lamprey spinal cord neurons (Sigvardt et al., 1985). In addition, the natural activation of swimming seems to depend on a transmitter acting at NMDA and kainate receptors (Brodin and Grillner, 1985). An understanding of the synaptic mechanisms underlying the activation of these receptors is therefore of obvious interest.

In the Xenopus embryo, motoneurons receive dual component EPSPs, consisting of fast and slow components mediated by kainate/quisqualate and NMDA receptors, respectively (Dale and Roberts, 1985). These EPSPs play an important role in generating the excitatory drive received by motoneurons during swimming in these embryos. Given that NMDA and kainate receptors are involved in the control of swimming in the lamprey, it seemed reasonable to ask whether they could also mediate components of excitation in lamprey neurons similar to those seen in the Xenopus embryo.

We have used focal extracellular stimulating electrodes to stimulate single axons in the lamprey spinal cord and evoke small unitary EPSPs in spinal cord neurons. In this paper, we describe 3 classes of amino acid-mediated EPSP that are almost identical in shape, time course, and pharmacology to those seen in the Xenopus embryo and consist of similar underlying kainate and NMDA receptor-mediated fast and slow components. This suggests that it may be a general role for kainate and NMDA receptors to generate fast and slow time course EPSPs, respectively.

\section{Materials and Methods}

Specimens of Ichthyomyzon unicuspis about $20 \mathrm{~cm}$ long were used for these experiments. Pieces of spinal cord 6-8 segments long were isolated from the notochord using the methods of Wallén ct al. (1985), mounted ventral side up and bathed in a magnesium-free saline containing 91 $\mathrm{mm} \mathrm{NaCl}, 2.1 \mathrm{~mm} \mathrm{KCl}, 20 \mathrm{~mm} \mathrm{NaHCO}_{3}, 5 \mathrm{~mm} \mathrm{CaCl}_{2}$, and $4 \mathrm{~mm}$ glucose, which was bubbled with $95 \% \mathrm{O}_{2} / 5 \% \mathrm{CO}_{2}$ and had a pH of 7.4. The temperature of the saline was between 7 and $9^{\circ} \mathrm{C}$.

\section{Stimulating electrodes}

Carbon fiber stimulating electrodes were made using the methods of Armstrong-James and Millar (1979). The carbon fiber ( $7 \mu \mathrm{m}$ diameter) was etched back in chromic acid under constant visual inspection to a fine short point that just protruded from the glass sheath. Silver conducting paint (Johnson Matthey, Mattheylec) was applied to the outside 
A

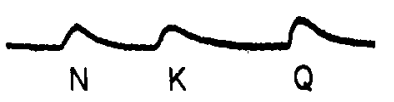

B

Figure 1. Effect of excitatory amino acid antagonists on agonist-evoked depolarizations of lamprey spinal neurons. The depolarizations evoked by the agonists NMA $(N)$, kainate $(K)$, and quisqualate $(Q)$ are shown before the later application of antagonist (left column), after maximal effect of the antagonist (middle column), and after maximal recovery from the effects of the antagonist (right column). $A$, Effect of $100 \mu \mathrm{M}$ 2-amino-5-phosphonovaleric acid (APV). B, Effect of 1.8 mм $\mathrm{Mg}^{2+}$. The slight depression of the quisqualate response was not seen in other neurons. $C$, Effect of $2 \mathrm{~mm}$ cis-2,3-piperidine dicarboxylic acid (PDA). D, Effect of $2 \mathrm{~mm}$ kynurenic acid (KYAC).

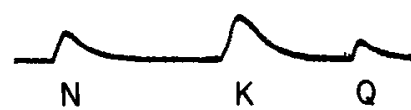

C

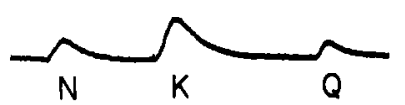

$\mathrm{D}$

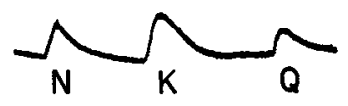

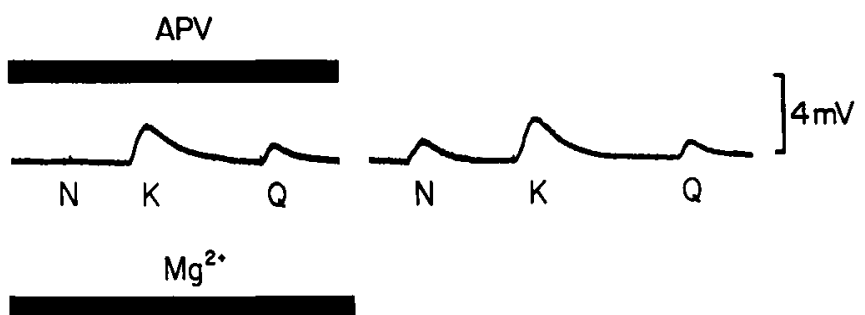

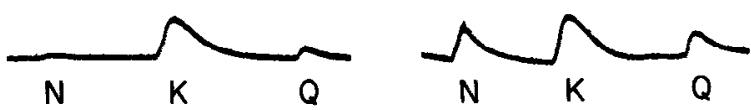

PDA

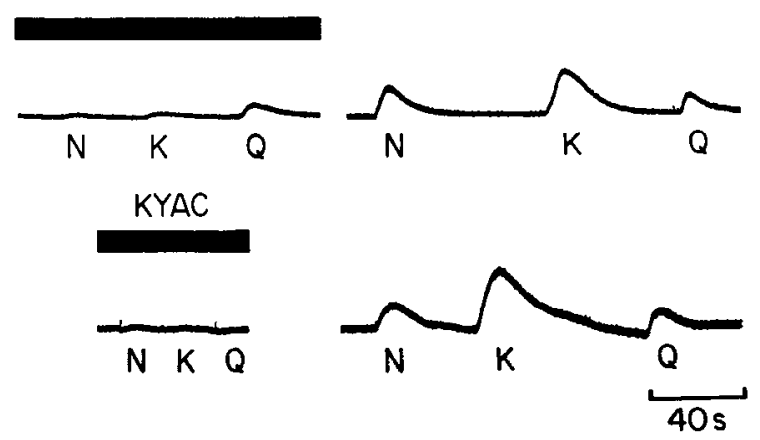

of the electrode as close to its tip as possible. This coating formed the indifferent part of the electrode and also acted as a screen. Electrical contact to the carbon fiber was made via silver-doped, conducting, epoxy glue (Johnson Matthey, Mattheylec).

\section{Electrophysiological recordings}

Conventional equipment was used to make intracellular recordings, the results being stored on a 7 channel Racal FM tape recorder for later analysis. Initially, electrodes filled with $5 \%$ Lucifer yellow in $0.3 \mathrm{M} \mathrm{LiCl}$, beveled or broken to a resistance of 100-200 M , were used to effect an anatomical identification of the recorded neurons. In later experiments, lower resistance, and consequently less noisy, electrodes filled with $3 \mathrm{M} \mathrm{KCl}$ were used $(30-80 \mathrm{M} \Omega$ ). In these experiments the recorded neurons were identified (if possible) by physiological means: motoneurons, by recording spikes in the adjacent ventral root that followed 1 for 1 spikes evoked by intracellular current injection in the motoneuron somata, and CC interneurons by orthodromic tracing of a caudally projecting, crossed axon (Buchanan, 1982). A total of 37 different EPSPs recorded in 31 neurons in 20 preparations were analyzed. Thirteen of these neurons were anatomically or physiologically identified as mo-

Table 1. Effects of excitatory amino acid antagonists of NMA-, kainate-, and quisqualate-evoked depolarizations of spinal neurons, expressed as mean percentage reductions of control responses

\begin{tabular}{cccc} 
& \multicolumn{3}{c}{ Reduction of control response (\%) } \\
\cline { 2 - 4 } & NMA & Kainate & Quisqualate \\
\hline APV, 100 & 99 & $4^{*}$ & $20^{*}$ \\
$(n=3)$ & $(1.3)$ & $(4.0)$ & $(18.7)$ \\
$\mathrm{Mg}^{2+}, 1.8 \mathrm{mM}$ & 90 & $5^{*}$ & $13^{*}$ \\
$(n=3)$ & $(4.6)$ & $(2.6)$ & $(9.7)$ \\
$\mathrm{PDA}, 2 \mathrm{mM}$ & 95 & 95 & $30^{*}$ \\
$(n=3)$ & $(4.7)$ & $(1.5)$ & $(23.5)$ \\
$\mathrm{KYAC}, 2 \mathrm{mM}$ & 100 & 100 & 94 \\
$(n=3)$ & $(0.0)$ & $(0.0)$ & $(3.1)$ \\
\hline
\end{tabular}

The numbers in parentheses represent SEM; asterisk indicates that the effect was not statistically significant $(P>0.1)$. toneurons and 2 as $\mathrm{CC}$ interneurons, the identity of the remainder being unknown.

Permanent records of EPSPs for illustration and analysis were made using a Kikusui digital storage oscilloscope and a Phillips $X-Y$ recorder.

\section{Pharmacology}

All experiments were performed in magnesium-free salines containing $5 \mathrm{mM} \mathrm{Ca}^{2+}$ and $5 \times 10^{-6} \mathrm{M}$ strychnine nitrate. In order to be able to study EPSPs in isolation, strychnine was used to block any IPSPs that might interfere. The strychnine could cause a considerable amount of spontaneous synaptic activity in spinal neurons. In some experiments, this was avoided by applying strychnine only to the 1 or 2 segments immediately surrounding the recorded neurons. This was done by enclosing these segments in a continually superfused pool, sealed from the rest of the bath. The rest of the spinal cord in these cases was "inactivated" by bathing it either in a saline containing $5 \mathrm{mM} \mathrm{Mn}^{2+}$ or $2 \mathrm{~mm}$ glycine and no $\mathrm{Ca}^{2+}$ in order to block synaptic transmission (see Rovainen, 1985). In other experiments, the use of salines containing 20 $\mathrm{mM} \mathrm{Ca}{ }^{2+}$ greatly reduced the level of spontaneous synaptic activity.

The amino acid antagonists 2-amino-5-phosphonovaleric acid (APV), cis-2,3-piperidine dicarboxylic acid (PDA) (both obtained from Cambridge Research Biochemicals), kynurenic acid (Sigma), and $\mathbf{M g}^{2+}$ were applied in the bathing medium via a superfusion system driven by a peristaltic pump. In some later experiments, small quantities $(2-5 \mathrm{nl})$ of $10 \mathrm{~mm}$ APV or $50 \mathrm{~mm}$ PDA (in saline) were applied close to the recorded neuron by pressure ejection from a multibarrelled micropipette (Neuro Phore). This gave similar results to bath application of antagonists but was very much quicker to perform. The amino acid agonists $N$-methyl-D,L-aspartate (NMA), kainate, and quisqualate were obtained from Sigma.

\section{Results}

\section{Excitatory amino acid receptors present on lamprey spinal neurons}

In order to see which amino acid receptors were present on lamprey spinal neurons and to investigate the specificities of the excitatory amino acid antagonists that have been used in other vertebrates, neurons were penetrated in salines containing $3 \times$ $10^{-6} \mathrm{M}$ TTX and no $\mathrm{Mg}^{2+}$. A multibarreled pressure-ejection micropipette was made, which contained, in separate barrels, 


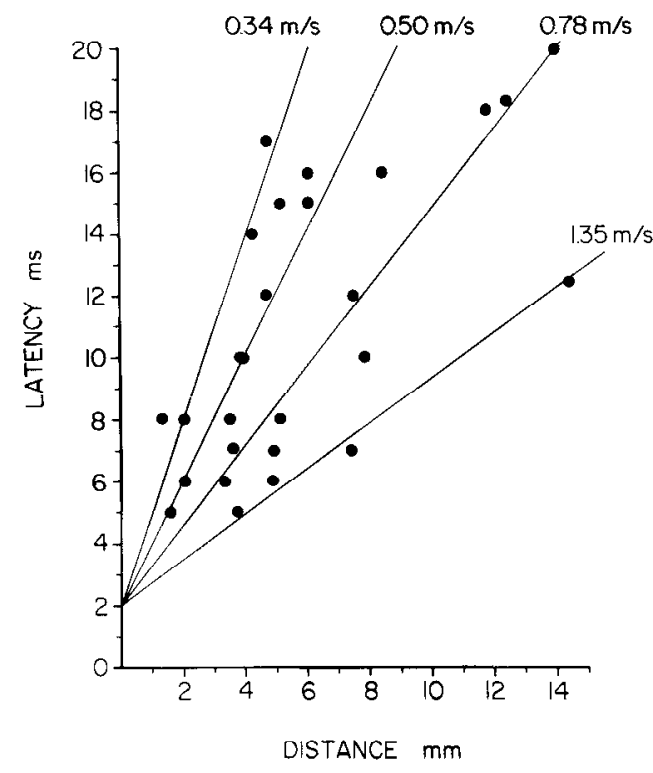

Figure 2. Latency of EPSPs plotted against the distance separating the stimulating and recording electrodes. A series of hypothetical lines have been drawn through the points to show how these EPSPs could have been evoked by axons having conduction velocities between 0.34 and $1.35 \mathrm{~m} / \mathrm{sec}$ and a synaptic delay of $2 \mathrm{msec}$.

solutions of $1 \mathrm{~mm}$ NMA, $0.1 \mathrm{~mm}$ kainate, and $0.1 \mathrm{~mm}$ quisqualate in saline. Once a neuron had been penetrated, the multibarreled pipette was placed near the neuron so that brief pressure pulses $(0.1-2 \mathrm{sec})$ would eject the agonists and give reproducible results. The amount of each agonist ejected was adjusted to give similar responses (1-5 nl for NMA and kainate, $0.5 \mathrm{nl}$ for quisqualate). The antagonists could then be run into the bath and their effect on the agonist-evoked depolarization of neurons examined.

APV, $100 \mu \mathrm{M}$, reversibly blocked the response of neurons to NMA but had no significant effect on responses to kainate or quisqualate (Fig. $1 A$, Table 1). Similarly, $1.8 \mathrm{~mm} \mathrm{Mg}^{2+}$, when added back to the bathing medium, also blocked responses to NMA but had no statistically significant effect on the response of neurons to kainate or quisqualate (Fig. $1 B$, Table 1). PDA, $2 \mathrm{mM}$, blocked responses to NMA and kainate but had only a small effect on responses to quisqualate (Fig. 1C, Table 1), while $2 \mathrm{mM}$ kynurenic acid blocked responses to NMA, kainate, and quisqualate (Fig. 1D, Table 1). Lamprey spinal cord neurons therefore possess NMDA, kainate, and quisqualate receptors. APV and $\mathrm{Mg}^{2+}$ act specifically at NMDA receptors in the lamprey as in other vertebrates (Ault et al., 1980; Davies et al., 1981); PDA seems to be an antagonist that acts preferentially at NMDA and kainate receptors (Davies et al., 1980), while kynurenic acid acts at all 3 receptors (Ganong et al., 1983; Perkins and Stone, 1982). The excitatory amino acid receptors present on lamprey spinal neurons appear, therefore, to be similar in pharmacological properties to those found in many other vertebrates (see Watkins and Evans, 1981, for review).

\section{Focal stimulation of axons}

The tip of the stimulating electrode was placed on the ventral surface of the spinal cord and gradually driven into the tissue until a small stimulus current pulse $0.05-1.0 \mathrm{msec}$ long could reliably evoke a small PSP in an intracellularly recorded neuron. If this was not possible, the electrode was withdrawn from the spinal cord and moved to another position, and the same procedure was repeated until a reliable potential could be evoked. Successful stimulating positions were found in an intermediate
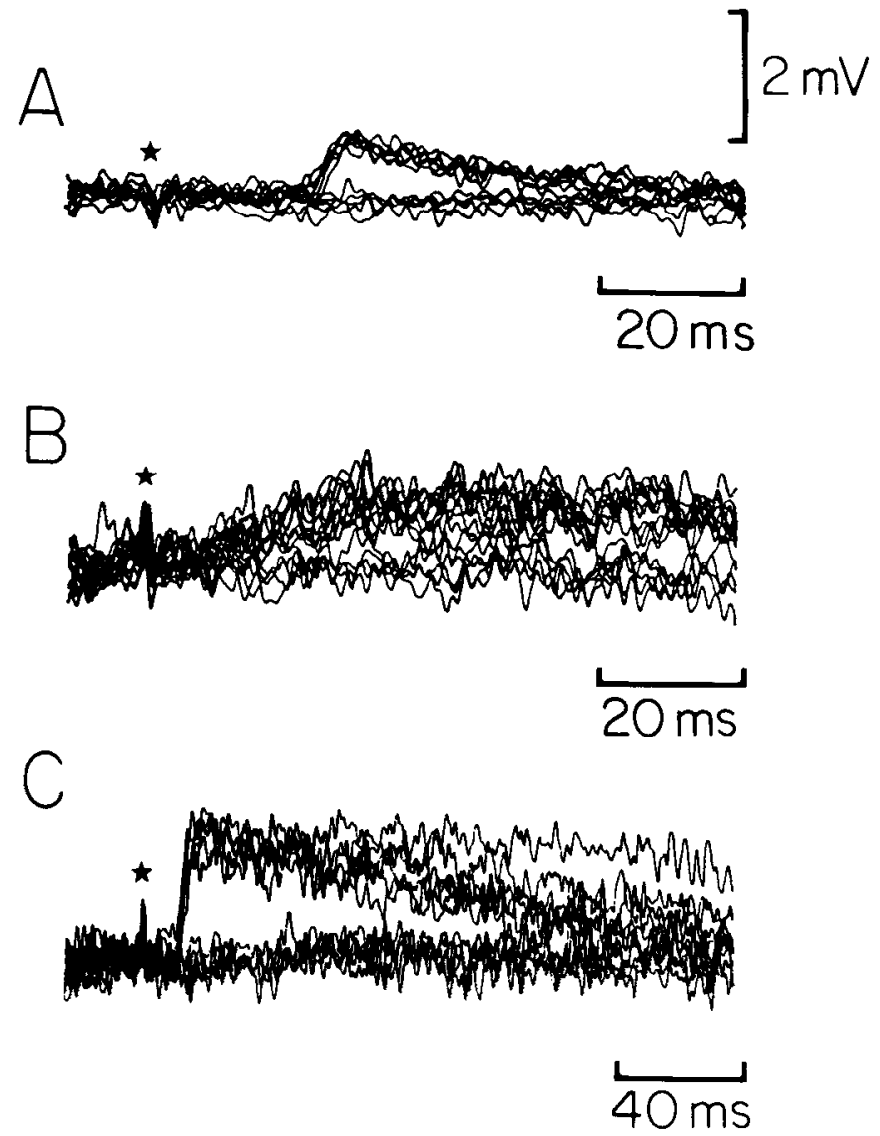

Figure 3. The all-or-nothing nature of the EPSPs evoked by extracellular stimulation. $A$, Fast EPSP, 10 consecutive stimuli delivered either just below or at threshold. $B$, Slow EPSP, 16 consecutive stimuli delivered either just below or at threshold. $C$, Mixed EPSP, 10 consecutive stimuli delivered either just below or at threshold. Star marks the stimulus artifact.

region lying in between the lateral edge and the midline and were often located over the gray matter.

The evoked PSPs were small, having an amplitude between 0.3 and $2.5 \mathrm{mV}$, and followed the stimulating pulse at constant latency (Figs. 3, 4). The latencies ranged from 5 to $20 \mathrm{msec}$, depending on the distance separating the recording and stimulating electrodes $(1.5-13.5 \mathrm{~mm})$. The evoked PSPs were probably excitatory. It was not possible to reverse them by injection of depolarizing current through the recording electrode, they were not blocked by strychnine, and they were not changed in shapc or sizc by the usc of $3 \mathrm{M} \mathrm{KCl}$ electrodes. These facts suggest that they were not dependent on a chloride conductance. The EPSPs may have been monosynaptic. First, they followed the stimulus pulse at a short and constant latency. Second, similar EPSPs could be evoked at similar latencies in salines containing $20 \mathrm{mM} \mathrm{Ca}^{2+}$. This treatment raises the threshold of neurons and has been used as a test of monosynaptic transmission (Mackler and Selzer, 1985; see Berry and Pentreath, 1976, for review). Third, a plot of latency versus the distance separating the electrodes (Fig. 2) showed that, assuming a synaptic delay of $2 \mathrm{msec}$ (a reasonable estimate in this preparation at 7 $9^{\circ} \mathrm{C}$; Buchanan, 1982; Rovainen, 1974), a series of lines could be drawn through the points to give a range of conduction velocities between 0.34 and $1.35 \mathrm{~m} / \mathrm{sec}$ (Fig. 2).

Many of the EPSPs had a clear unitary nature: They appeared all-or-nothing at a distinct threshold and did not change shape or size if the stimulus was raised slightly above threshold (Fig. 

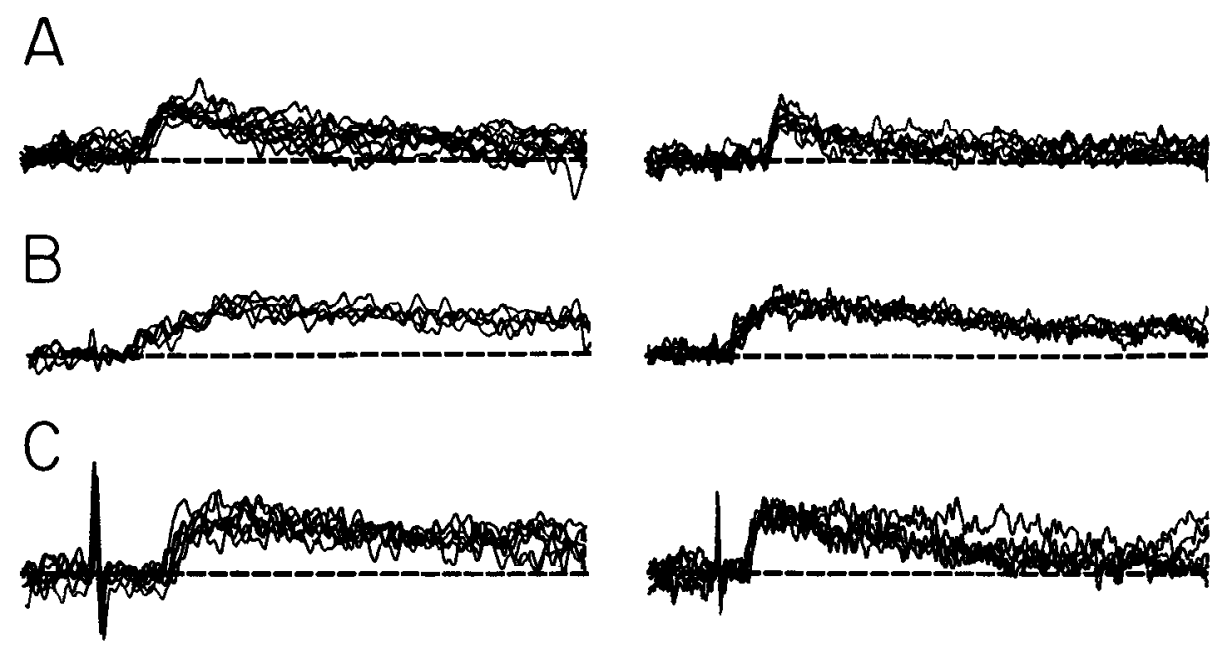

Figure 4. The 3 types of unitary EPSP evoked by extracellular stimulation: $A$, Fast EPSP; $B$, slow EPSP; $C$ and $D$, two different mixed EPSPs, demonstrating the range of shapes these EPSPs can have. Each EPSP is shown at 2 different time bases. The broken line in this and all subsequent figures indicates the resting potential. Scale bar: $A, B$, and $D, 1 \mathrm{mV} ; C, 2$ $\mathrm{mV}$.
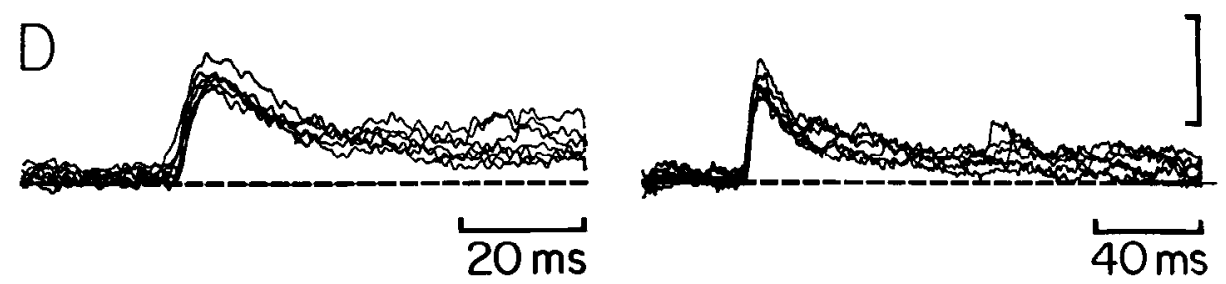

3). This suggests that these EPSPs were produced by a single spike in a single presynaptic axon. Some EPSPs were so small that it was impossible to tell whether they were all-or-nothing in appearance since any interposed sizes of EPSP could have been lost in the noise of the records. In addition to this evidence favoring the unitary nature of these EPSPs, they were similar in shape and size to EPSPs evoked by intracellular stimulation of single axons ( $\mathrm{N}$. Dale and J. T. Buchanan, personal observations) and to IPSPs and EPSPs evoked by lateral and CC interneurons (Buchanan, 1982; Rovainen, 1974).

The strengths of stimulus current needed to evoke unitary EPSPs were usually lower than those needed to evoke axon spikes in suction electrodes placed ipsilaterally around the caudal and/or rostral ends of the spinal cord. This suggests that either the axons that evoked the EPSPs did not project to the recording electrodes or were too small to be recorded by such an electrode. In no case was it possible to correlate 1:1 the

Table 2. Amplitude and time course of the 3 categories of unitary EPSP

\begin{tabular}{clcl} 
EPSP type & $\begin{array}{l}\text { Amplitude } \\
(\mathrm{mV})\end{array}$ & $\begin{array}{l}\text { Rise time } \\
(\mathrm{msec})\end{array}$ & $\begin{array}{c}\text { Half-decay } \\
\text { time (msec) }\end{array}$ \\
\hline Fast & 0.8 & 6.5 & 22.5 \\
$(n=13)$ & $(0.3-1.4)$ & $(3-12)$ & $(10-52)$ \\
& $(0.41)$ & $(3.58)$ & $(12.16)$ \\
Slow & 0.7 & 28.0 & 109.0 \\
$(n=11)$ & $(0.5-1.3)$ & $(16-48)$ & $(70-136)$ \\
& $(0.22)$ & $(9.21)$ & $(21.52)$ \\
Mixcd & 1.3 & 12.0 & 105.0 \\
$(n=13)$ & $(0.5-2.4)$ & $(4-20)$ & $(28-280)$ \\
& $(0.61)$ & $(7.33)$ & $(68.7)$ \\
\hline
\end{tabular}

Five examples of each type of EPSP were recorded in identified motoneurons; in addition, 2 slow and 2 mixed EPSPs were recorded in identified CC interneurons. Each value is expressed as a mean with the range of estimates and the SD shown in brackets underneath. appearance of a spike in the ipsilateral spinal cord electrode with that of a unitary EPSP.

The unitary EPSPs evoked by focal stimulation could be grouped into 3 categories depending on their time course. "Fast" EPSPs had a rise time between 3 and $12 \mathrm{msec}$ (mean, $6.5 \mathrm{msec}$ ), a half-decay time of between 10 and $52 \mathrm{msec}$ (mean, $22.5 \mathrm{msec}$ ), and a mean amplitude of $0.8 \mathrm{mV}$ (Table 2, Fig. $4 A$ ). "Slow" EPSPs had a rise time between 16 and $46 \mathrm{msec}$ (mean, 28.0 $\mathrm{msec}$ ), a long falling phase at least $200 \mathrm{msec}$ long with a halfdecay time between 70 and $136 \mathrm{msec}$ (mean, $109.0 \mathrm{msec}$ ), and a mean amplitude of $0.7 \mathrm{mV}$ (Table 2, Fig. $4 B$ ). The last category of unitary EPSP (Fig. 3C), the "mixed" potentials, had a rise time (to the first point of inflection, judged by eye) between 4 and $20 \mathrm{msec}$ (mean, $12.0 \mathrm{msec}$ ), a long falling phase of at least $200 \mathrm{msec}$ with a half-decay time between 28 and $280 \mathrm{msec}$ (mean, $105.0 \mathrm{msec}$ ), and a mean amplitude of $1.3 \mathrm{mV}$ (Table 2; Fig. 4, $C, D$ ).

Within each category of EPSP there could be considerable variation in rise and half-decay times (see Table 2). This may depend on where in the dendritic tree an EPSP is generated. Medium-sized lamprey neurons, including motoneurons and CC interneurons, have large dendritic trees (Buchanan, 1982; Wallén et al., 1985). The range of shapes of mixed EPSPs seemed greater than those of the fast and slow potentials (compare Fig. 4, $C$ and $D$ ). Some mixed EPSPs could have very short rise times, while others had longer rise times with 2 points of inflection, the second occurring between 30 and $50 \mathrm{msec}$ after the slart of the PSP (Figs. 4, $C$ and $D ; 8 C$ ). While all mixed EPSPs lasted at least $200 \mathrm{msec}$, the shape of the falling phase showed great variety. Some mixed EPSPs gradually decayed back to zero and had long half-decay times (Figs. $4 C$ and $8 B$ ). In others, the falling phase had 2 parts, an initial period of fast decay followed by a long period of slow decay (Fig. $4 D$ ). These mixed EPSPs had short half-fall times. We think that these differences in shape are due to the mixed EPSPs consisting of different numbers of underlying fast and slow components (see later, and Dale and Roberts, 1985).

If the stimulus current was increased markedly above the level required to evoke unitary EPSPs, more axons were stimulated 
and axon spikes appeared in the spinal cord suction electrode (Fig. 5). The amplitude of the EPSP grew much larger and its duration longer, greatly outlasting any discharge of spikes seen in the spinal cord electrode (Fig. 5). Often the latency of the EPSP would shorten with higher stimulus intensity (Fig. 5), presumably because larger, faster-conducting fibers more distant from the stimulating electrode were recruited.

\section{Pharmacology of EPSPs}

\section{Fast EPSPS}

The addition to the bathing medium of $100 \mu \mathrm{M}$ APV $(n=9)$, or $1.8 \mathrm{mM} \mathrm{Mg}^{2+}(n=2)$ had no effect on either the duration or amplitude of the fast EPSPs (Fig. 6). However, 2 mм PDA reversibly caused a great reduction of the EPSP amplitude: mean $\pm \mathrm{SD}, 86 \pm 14.1 \%\left(n=5\right.$, Fig. 6). Since APV and $\mathrm{Mg}^{2+}$ could block responses to exogenous NMA but had no effect on the fast EPSPs, they would seem to be generated by a transmitter acting at non-NMDA receptors. These EPSPs may be mediated by kainate, rather than quisqualate, receptors since they were greatly reduced by PDA, which in this system blocked the response of neurons to exogenous kainate but had little effect on their response to exogenous quisqualate (Fig. 1C).

\section{Slow EPSPS}

Bath application of $100 \mu \mathrm{M}$ APV $(n=5)$ caused a reversible reduction of $67 \pm 7.8 \%(n=5)$ in the amplitude of slow EPSPs (Fig. 7). In 4 cases, $1.0-1.8 \mathrm{~mm} \mathrm{Mg}^{2+}$ also caused a similar reduction in EPSP amplitude $(81 \pm 22.7 \%, n=4$; Fig. 7$)$. The slow EPSPs would therefore seem to be generated by a transmitter acting at NMDA receptors.

\section{Mixed EPSPS}

Both $100 \mu \mathrm{M}$ APV and $1.0-1.8 \mathrm{mM} \mathrm{Mg}^{2+}$ revealed the dualcomponent nature of the mixed EPSP. APV caused only a slight but statistically insignificant $(p>0.1)$ reduction in EPSP amplitude $(10 \pm 19 \% ; n=8)$. However, it greatly reduced the falling phase of the EPSP (Fig. $8 B$ ), leaving a potential that had a short half-decay time $(35 \pm 13.5 \mathrm{msec}, n=7$; compare second arrow in Fig. 8). $\mathrm{Mg}^{2+}$ similarly had little effect on the amplitude of the mixed EPSPs (Fig. $8 \mathrm{C}$ ), causing a reduction of only $5 \pm 11.2 \%(n=5)$; like APV, however, it reduced the duration of the falling phase, leaving an EPSP with a half-decay time of $38.0 \pm 10.0 \mathrm{msec}(n=5$, Fig. 8 ). The EPSPs remaining in the presence of APV or $\mathrm{Mg}^{2+}$ looked very similar to the fast EPSPs described earlier. PDA, $2 \mathrm{~mm}$, antagonized both components of the mixed EPSP, causing a reduction in amplitude of $75 \%(n=3$; Fig. $8 A)$. The mixed EPSPs therefore seemed to consist of 2 underlying components. One was a fast potential, insensitive to APV or $\mathrm{Mg}^{2+}$, which could be blocked by PDA, and was thcrefore probably mediated by kainate receptors. The other was a slow component, which could be blocked by APV or $\mathrm{Mg}^{2+}$ and was therefore probably mediated by NMDA receptors. If we propose that mixed EPSPs can consist of different numbers of underlying fast and slow components, the range of shapes of mixed potentials can be explained. The mixed EPSPs with 2 points of inflection in their rising phase and long halfdecay times (e.g., Fig. $4 C$ ) would contain more slow than fast components, while those with only 1 point of inflection in their rising phase and short half-decay times would comprise more fast than slow ones (e.g., Fig. $4 D$; cf. Fig. 4 of Dale and Roberts, 1985).

The effects of the excitatory amino acid antagonists on the compound EPSPs evoked by higher stimulus currents were what might be expected from their effects on the unitary EPSPs. APV and $\mathrm{Mg}^{2+}$ greatly shortened the falling phase of compound potentials but had little effect on their amplitude, while PDA great-

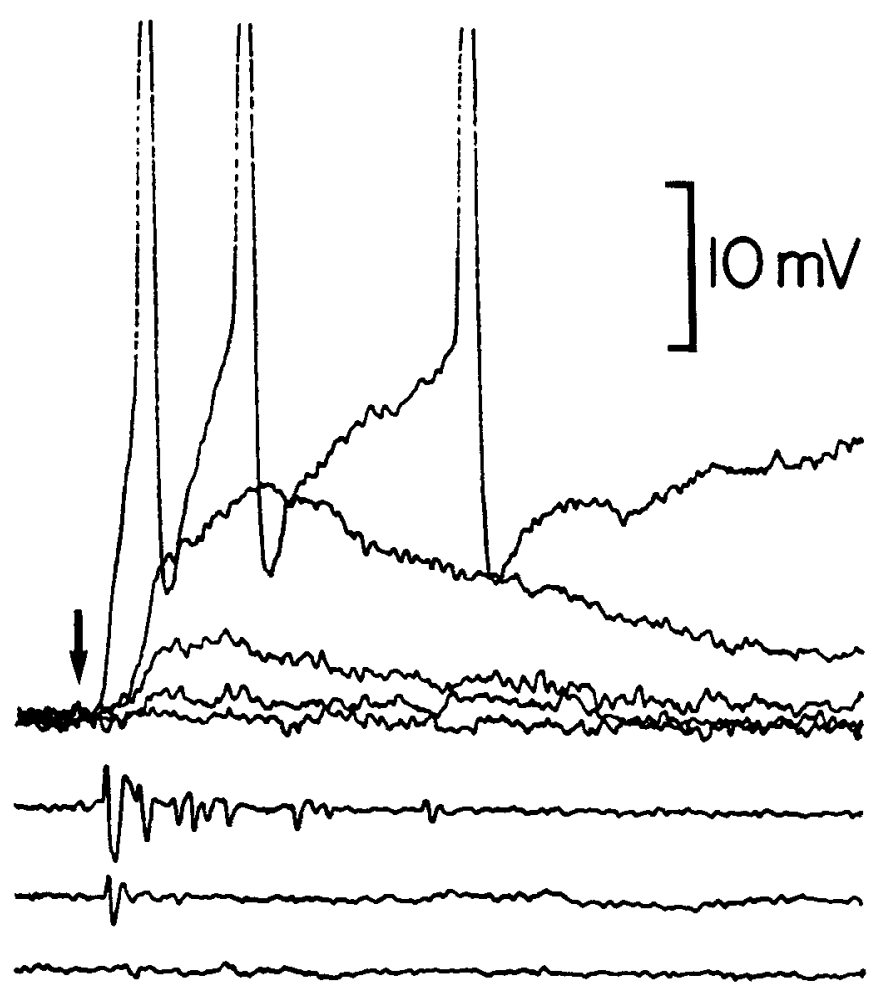

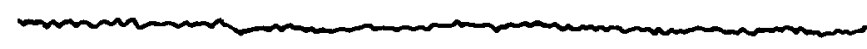

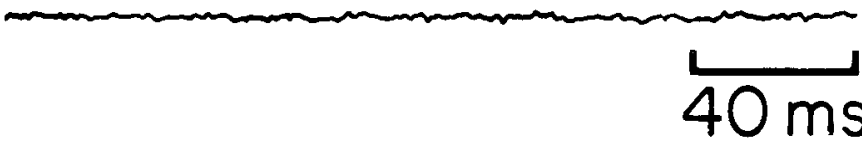

Figure 5. Effect of grading the stimulus current. The top set of traces shows the EPSPs evoked in an intracellularly recorded neuron; bottom five traces are from the ipsilateral caudal spinal cord electrode. The stimulus was graded from $2.4 \mathrm{~V}$, which was subthreshold and did not evoke any spikes in the spinal cord electrode (bottom trace); to $2.5 \mathrm{~V}$, which evoked a unitary EPSP; to $3 \mathrm{~V}$, which evoked a slightly larger EPSP; to $5 \mathrm{~V}$, which evoked a still larger EPSP and some large axon spikes in the spinal cord electrode; and to $10 \mathrm{~V}$, which evoked a short burst of spikes in the spinal cord electrode and a large, long-lasting EPSP that caused the neuron to firc some action potentials. Arrow marks the stimulus artifact.

ly reduced the amplitude of these compound EPSPs (Fig. 9). No EPSPs were observed that were not greatly reduced by PDA.

\section{Summation of EPSPs}

EPSPs summated when repetitive stimuli were delivered at 200 msec intervals or less. Sometimes they would summate in a predictable linear manner (Fig. 10A). However, usually there was facilitation of the EPSP amplitude throughout the stimulus train. This either occurred gradually (Fig. 10B) or suddenly in the middle of a stimulus train, with the amplitude of the EPSP increasing greatly to as much as $20 \mathrm{mV}$ and then slowly decaying back to zero (Fig. 10C). When this occurred, intense bursts of axon spikes were seen in recording electrodes placed on the ends of the spinal cord. This behavior occurred more readily at higher frequencies of stimulation and was never seen during application of excitatory amino acid antagonists. Furthermore, it did not occur when synaptic transmission was blocked in all but 1 or 2 segments of the spinal cord (see Materials and Methods). The cause of this facilitation is unknown; however, it would seem to be due to the firing of more axons. These could either be stimulated directly by the stimulating electrode or be recruited 

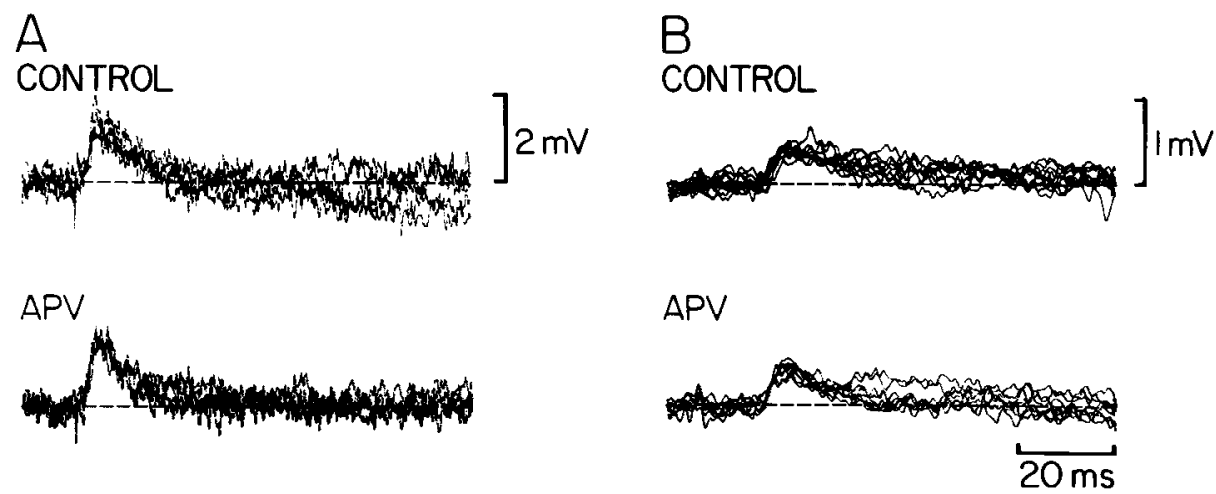

Figure 6. Pharmacology of fast EPSPs. A, Fast EPSP recorded in a motoneuron that was unaffected by $100 \mu \mathrm{M}$ APV (shown $10 \mathrm{~min}$ after APV was run into the bath). Application of 2 mM PDA (after the APV was washed out of the bath) greatly reduced the EPSP (shown 6 min after PDA was run into the bath). $B$, Application of $100 \mu \mathrm{M}$ APV for $12 \mathrm{~min}$ had no effect on a different fast EPSP recorded in a different neuron. $C$, Application of $1 \mathrm{mM} \mathrm{Mg}^{2+}$ for $15 \mathrm{~min}$ had no effect on a fast EPSP recorded in a different motoneuron. Note that the time base is different in $A, B$, and $C$.

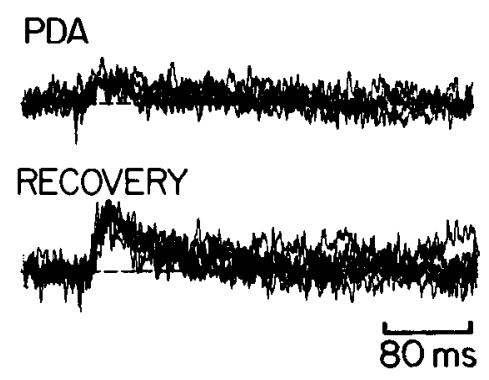

indirectly via some polysynaptic pathway. In view of the number of extra axons necessary to cause the great increases in amplitude seen, the second of these explanations seems more likely. This suggests that the repetitive firing of a single excitatory axon can lead to the firing of other excitatory interneurons. Similar phenomena have been observed during the repetitive firing of excitatory axons in the Xenopus embryo (Fig. 7 of Dale and Roberts, 1985).

\section{Discussion}

\section{Origin and role of EPSPS}

The axons that generated the unitary EPSPs probably had conduction velocities between 0.34 and $1.35 \mathrm{~m} / \mathrm{sec}$, and it was not possible to record them in spinal cord suction electrodes. This means that they were probably not large reticulospinal axons such as those of the Muller cells, which are fast conducting and can be easily recorded with spinal cord suction electrodes. Many medium-sized axons, such as those of the $\mathrm{CC}$ and lateral interneurons, can be readily recorded by such electrodes. We think that the axons were small in diameter and could have been those of propriospinal excitatory interneurons. Dale (1986) has shown that the lamprey spinal cord contains excitatory interneurons that fire during swimming, release a transmitter that activates NMDA and kainate receptors, and generate an oscillating excitatory drive in motoneurons. These results suggest that the individual components of this excitatory drive consist of kainate receptor-mediated fast EPSPs and NMDA receptor-mediated slow EPSPs. This is very similar to the Xenopus embryo, wherein excitatory interneurons can also generate fast and slow, kainate and NMDA receptor-mediated EPSPs that summate to produce the excitatory drive for swimming (Dale and Roberts, 1985).

\section{Dual-component EPSPS}

The mixed EPSPs consisted of 2 types of underlying component. Since they appeared to be unitary (Fig. $3 C$ ), they could have been produced by a single spike in a single presynaptic axon. We cannot exclude the possibility that 2 or more axons with identical thresholds were stimulated to produce an apparently unitary mixed EPSP. It is also possible that one or another of the components could have been gencratcd at a separate synapse by an interposed neuron. However, we favor the simple hypothesis that a single neuron can release an excitatory trans-
Figure 7. Pharmacology of slow EPSPs. $A$, Slow EPSP recorded in a motoneuron antagonized by $100 \mu \mathrm{M}$ APV (shown after 10 min of application). $B$, Slow EPSP recorded in a $\mathrm{CC}$ interneuron (premotor interneuron) antagonized by application of 1 $\mathrm{mM} \mathbf{M g}^{2+}$ for $6 \mathrm{~min}$.
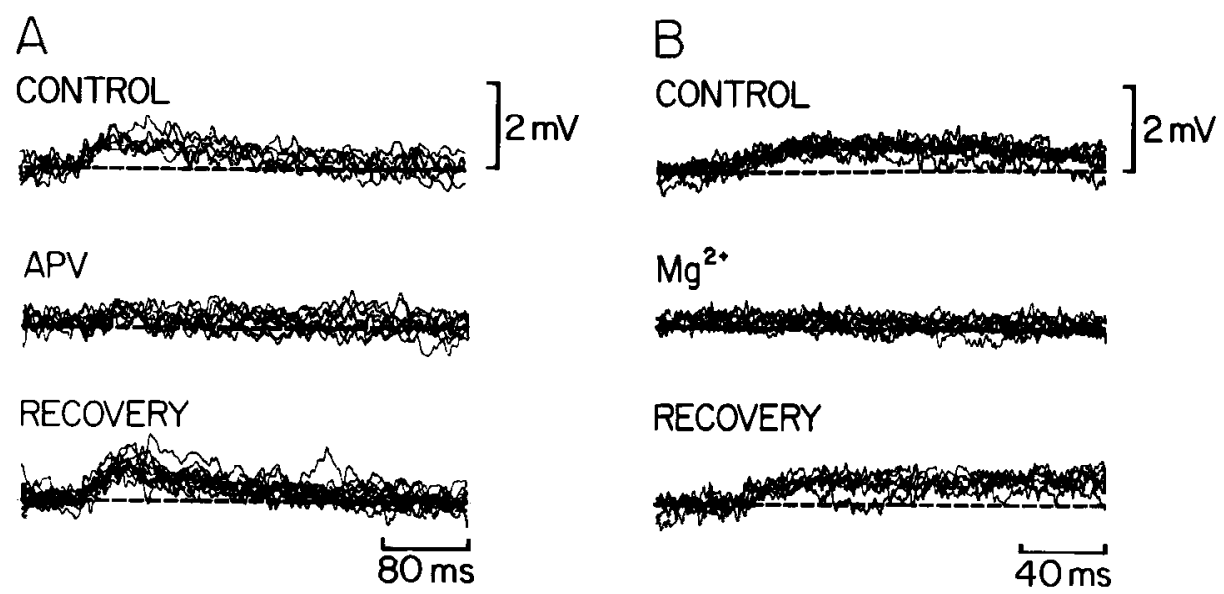

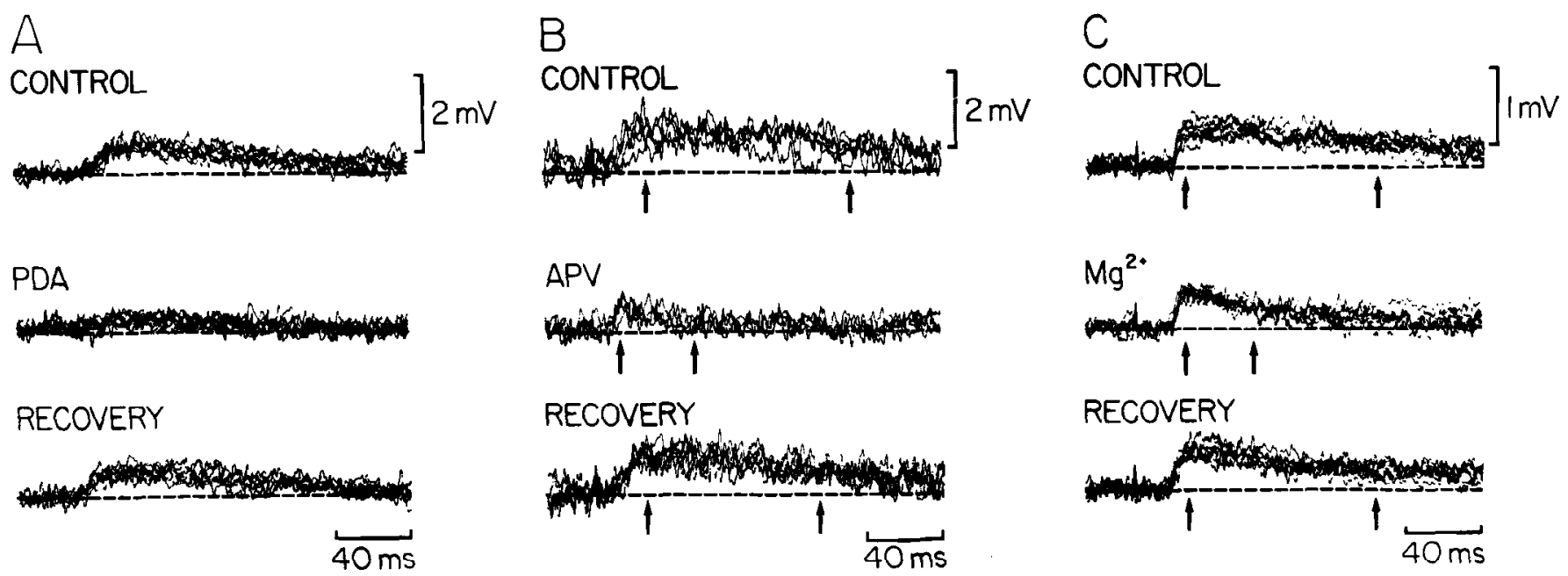

Figure 8. Pharmacology of mixed EPSPs. A, Mixed EPSP antagonized by $6 \mathrm{~min}$ of $2 \mathrm{~mm}$ PDA application. This EPSP was subsequently shown to consist of 2 components by the application of APV (not shown). Arrows in $B$ and $C$ indicate the points of peak depolarization and half-decay of the EPSPs. $B$, Effect of $6 \mathrm{~min}$ of $100 \mu \mathrm{M}$ APV on the shape and time course of a mixed EPSP recorded in a motoneuron. The falling phase of the neuron is considerably shortened. $C$. Effect of $8 \mathrm{~min}$ of $1 \mathrm{mM} \mathrm{Mg}^{2+}$ application on the shape and time course of a mixed EPSP recorded in a CC interneuron.

mitter that can act at 2 sorts of amino acid receptor, producing mixed EPSPs consisting of fast and slow components at a single physiological synapse. A similar hypothesis has been put forward to explain mixed EPSPs evoked by extracellular stimulation of axons and intracellular stimulation of single neurons in the Xenopus embryo (Dale and Roberts, 1985). Since physiological concentrations of $\mathrm{Mg}^{2+}$ greatly depressed the slow com-
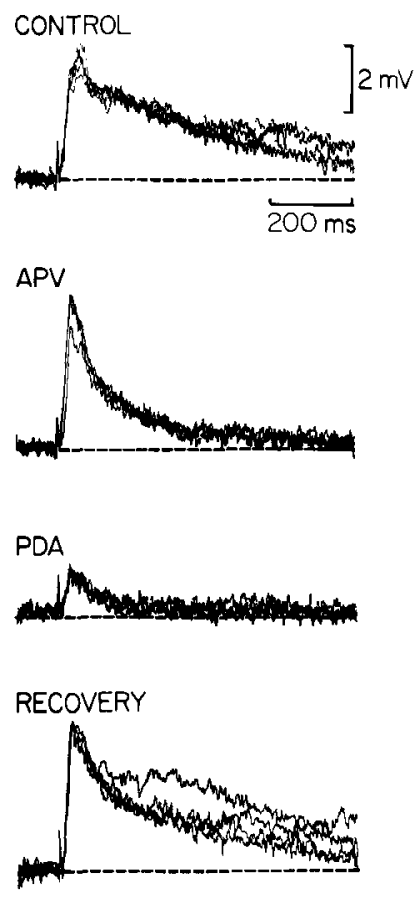

Figure 9. Pharmacology of compound EPSPs. A compound EPSP that was evoked at stimulus currents above those needed to evoke unitary EPSPs. Note that it is larger in amplitude and much longer in duration than the unitary EPSPs. APV, $100 \mu \mathrm{M}$, greatly shortened the falling phase of the EPSP, while 2 mM PDA (applied after recovery from the effects of APV, not shown) caused a great reduction in the amplitude of the EPSP. ponents of the mixed EPSPs (Fig. 8C), these dual-component EPSPs may only be seen in physiological salines lacking $\mathrm{Mg}^{2+}$. They may therefore be a much more common phenomenon than realized hitherto (see Herron et al., 1985). $\mathbf{M g}^{2+}$ imparts voltage sensitivity to NMDA receptor ion channels (Mayer et al., 1984; Nowak et al., 1984), an EPSP containing fast voltageinsensitive and slow voltage-sensitive components could there-

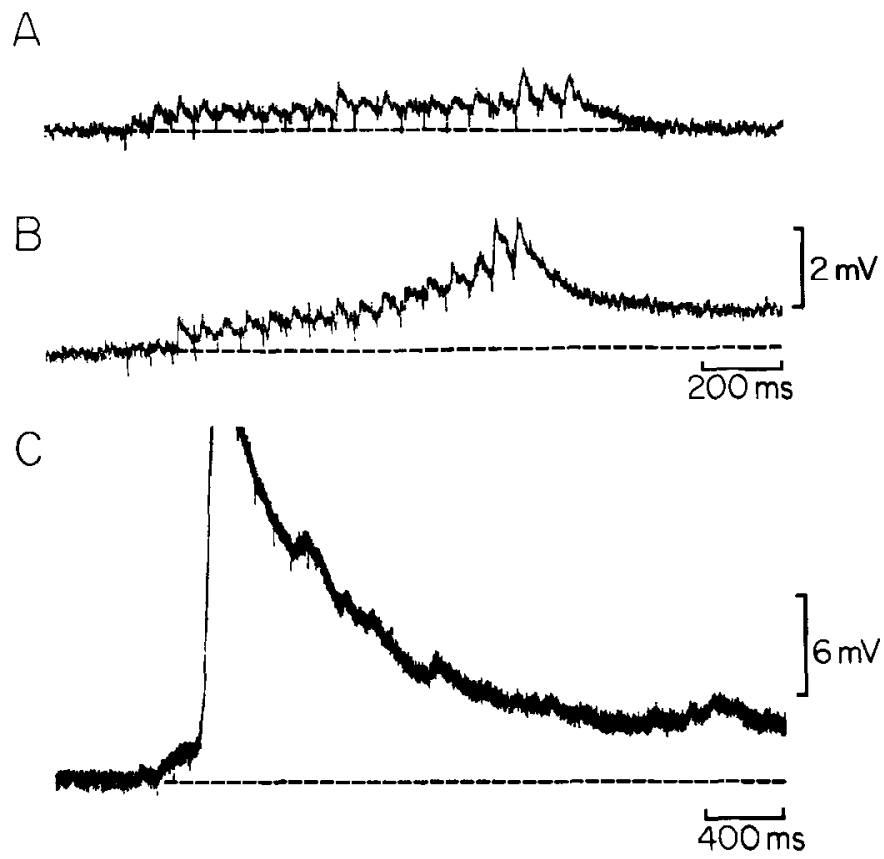

Figure 10. Temporal summation of unitary EPSPs. A, Train of stimuli delivered at $20 \mathrm{~Hz}$ evoking an EPSP that summated in a predictable way. $B$, Different train of stimuli, delivered at the same current strength to the same neuron, that resulted in gradual facilitation of the EPSP. $C$, Train of stimuli in a different neuron delivered at $10 \mathrm{~Hz}$ that resulted in a massive facilitation of the EPSP (the top few millivolts of the potential have been cut off by the recording machine) that slowly decayed back to the resting potential. 
fore have unusual integrative properties depending on the resting potential of the cell and any other simultaneous synaptic inputs.

\section{Comparison with amino acid-mediated}

EPSPs in other systems

Short-time-course EPSPs, probably limited in duration by the membrane time constant, have been reported in the rat dentate gyrus (Crunelli et al., 1982), CAl pyramidal neurons of the hippocampus (Collingridge et al., 1983), Xenopus embryo motoneurons (Dale and Roberts, 1985), and cat cortical neurons (Herrling, 1984). Like the fast EPSPs reported here, they seem to be mediated by kainate/quisqualate receptors. This suggests that these receptors could be involved generally in mediating short-time-course EPSPs.

Slow NMDA receptor-mediated EPSPs, with a time course much greater than the membrane time constant, have been seen in Xenopus embryo motoneurons (Dale and Roberts, 1985), cat cortical neurons (Thomson and Lodge, 1985), and in CA1 hippocampal neurons (Herron et al., 1985). These EPSPs have therefore been seen in animals ranging from the lamprey (one of the most primitive extant vertebrates) to mammals. This suggests that NMDA receptor ion channels could, in general, mediate slow EPSPs. In the presence of $\mathrm{Mg}^{2+}$, NMDA ion channels are voltage sensitive (Mayer et al., 1984; Nowak et al., 1984; $c f$. MacDonald et al., 1982). Since the NMDA receptor mediates slow EPSPs, it seems possible that the voltage properties of a cell could be dramatically changed over long time periods by presynaptic neurons that fire at low frequencies and release a transmitter that acts at NMDA receptors, causing a sustained activation of the NMDA ion channel. Two possible examples of this are the induction of pacemaker-like properties in cortical neurons (Flatman et al., 1983) and lamprey spinal neurons by exogenous NMA application (Sigvardt and Grillner, 1981; Sigvardt et al., 1985).

No EPSPs were found that were not affected by the excitatory amino acid antagonists. Furthermore, the excitatory drive for swimming in the lamprey may be wholly mediated by amino acid receptors (Dale, 1986). This, together with a plethora of evidence that amino acid transmitters may mediate excitation in many diverse parts of the nervous system, suggests that these transmitter systems must be of major importance in controlling neuronal function.

\section{References}

Armstrong-James, M., and J. Millar (1979) Carbon fibre microelectrodes. J. Neurosci. Methods 1: 279-288.

Ault, B., R. H. Evans, A. A. Francis, D. J. Oakes, and J. C. Watkins (1980) Selective depression of excitatory amino acid induced depolarizations by $\mathrm{Mg}^{2+}$ ions in isolated spinal cord preparations. $J$. Physiol. (Lond.) 307: 413-428.

Berry, M. S., and V. W. Pentreath (1976) Criteria for distinguishing between monosynaptic and polysynaptic transmission. Brain Res. 105: 1-20.

Brodin, L., and S. Grillner (1985) The role of putative excitatory amino acid neurotransmitters in the initiation of locomotion in the lamprey spinal cord. I. The effects of excitatory amino acid antagonists. Brain Res. 360: 139-148.

Brodin, L., S. Grillner, and C. M. Rovainen (1985) NMDA, kainate and quisqualate receptors and the generation of fictive locomotion in the lamprey spinal cord. Brain Res. 325: 302-306.

Buchanan, J. T. (1982) Identification of interneurons with contralateral, caudal axons in the lamprey spinal cord: Synaptic interactions and morphology. J. Neurophysiol. 47: 961-975.

Collingridge, G. L., S. J. Kehl, and H. McLennan (1983a) The antagonism of amino acid induced excitations of rat hippocampal neurons in vitro. J. Physiol. (Lond.) 334: 19-31.

Collingridge, G. L., S. J. Kehl, and H. McLennan (1983b) Excitatory amino acids in synaptic transmission in the Schaffer collateral-com- missural pathway of the rat hippocampus. J. Physiol. (Lond.) 334: 33-46.

Crunelli, V., S. Forda, G. L. Collingridge, and J. S. Kelly (1982) Intracellular recorded synaptic antagonism in the rat dentate gyrus. Nature 300: 450-452.

Dale, N. (1986) Excitatory synaptic drive for swimming mediated by amino acid receptors in the lamprey. J. Neurosci. 6: 2662-2675.

Dale, N., and A. Roberts (1984) Excitatory amino acid receptors in Xenopus embryo spinal cord and their role in the activation of swimming. J. Physiol. (Lond.) 348: 527-543.

Dale, N., and A. Roberts (1985) Dual-component amino acid-mediated synaptic potentials: Excitatory drive for swimming in Xenopus embryo. J. Physiol. (Lond.) 363: 35-59.

Davies, J., and J. C. Watkins (1981) Pharmacology of glutamate and aspartate antagonists on cat spinal neurons. In Glutamate as a Neurotransmitter, C. Di Chiara and G. L. Gessa, eds., pp. 275-284, Raven Press, New York.

Davies, J., and J. C. Watkins (1983) Role of excitatory amino acid receptors in mono- and polysynaptic excitation in the cat spinal cord. Exp. Brain Res. 49: 280-290.

Davies, J., R. H. Evans, A. A. Francis, A. W. Jones, and J. C. Watkins (1980) Excitatory amino acid receptors in the vertebrate CNS. In Neurotransmitters and Their Receptors, U. Z. Littauer, ed., pp. 333347, John Wilcy, New York.

Davies, J., A. A. Francis, A. W. Jones, and J. C. Watkins (1981) 2-Amino-5-phosphonovalerate (APV), a potent and selective antagonist of amino acid-induced and synaptic excitation. Neurosci. Lett. 21: $77-81$.

Flatman, J. A., P. C. Schwindt, W. E. Crill, and C. E. Stafstrom (1983) Multiple actions of $\mathrm{N}$-methyl-D-aspartate on cat neocortical neurons in vitro. Brain Res. 266: 169-173.

Ganong, A. H., T. H. Lanthorn, and C. W. Cotman (1983) Kynurenic acid inhibits synaptic and amino acid induced responses in the rat hippocampus and spinal cord. Brain Res. 273: 170-174.

Grillner, S., A. McClellan, K. Sigvardt, P. Wallén, and M. Wilen (1981) Activation of NMDA receptors elicits 'fictive locomotion' in lamprey spinal cord in vitro. Acta Physiol. Scand. 113: 549-551.

Herrling, P. L. (1984) Evidence that the cortically evoked epsp in cat caudate neurons is mediated by non-NMDA excitatory amino acid receptor. J. Physiol. (Lond.) 353: 98P.

Herrling, P. L., R. Morris, and T. E. Salt (1983) Effects of excitatory amino acids and their antagonists on membrane and action potentials of cat caudate neurons. J. Physiol. (Lond.) 339: 207-222.

Herron, C. E., R. A. J. Lester, E. J. Coan, and G. L. Collingridge (1985) Intracellular demonstration of an N-methyl-D-aspartate receptor mediated component of synaptic transmission in the rat hippocampus. Neurosci. Lett. 60: 19-23.

MacDonald, J. F., A. V. Porietis, and J. M. Wojtowicz (1982) L-Aspartic acid induces a region of negative slope conductance in the current voltage relationship of cultured spinal cord neurones. Brain Res. 237: 248-253.

Mackler, S. A., and M. E. Selzer (1985) Regeneration of functional synapses between individual recognizable neurones in the lamprey spinal cord. Science 229: 774-776.

Mayer, M. L., G. L. Westbrook, and P. B. Guthrie (1984) Voltagedependent block by $\mathrm{Mg}^{2+}$ of NMDA responses in spinal cord neurones. Nature 309: 261-263.

McLennan, H. (1983) Receptor for the excitatory amino acids in the mammalian central nervous system. Prog. Neurobiol. 20: 251-272.

Nowak, L., P. Bregestovski, P. Ascher, A. Herbert, and A. Prochiantz (1984) Magnesium gates glutamate-activated channels in mouse central neurones. Nature 307: 462-465.

Perkins, M. N., and T. W. Stone (1982) Iontophoretic investigation of the actions of convulsant kynurenines and their interaction with the endogenous excitant quinolinic acid. Brain Res. 247: 184-187.

Poon, M. L. T. (1980) Induction of swimming in lamprey by L-DOPA and amino acids. J. Comp. Physiol. 136: 337-344.

Rovainen, C. M. (1974) Synaptic interactions of identified nerve cells in the spinal cord of the sea lamprey. J. Comp. Neurol. 154: 189206.

Rovainen, C. M. (1985) Effects of groups of propriospinal interneurones on fictive swimming in the isolated spinal cord of the lamprey. J. Neurophysiol. 54: 959-977.

Sigvardt, K. A., and S. Grillner (1981) Spinal neuronal activity during fictive locomotion in the lamprey. Soc. Neurosci. Abstr. 7: 362. 
Sigvardt, K. A., S. Grillner, P. Wallén, and P. A. M. van Dongen (1985) Activation of NMDA receptors elicits fictive locomotion and bistable membrane properties in the lamprey spinal cord. Brain Res. 336: 390-395.

Slaughter, M. M., and R. F. Miller (1983) The role of excitatory amino acid neurotransmitters in the mud puppy retina: An analysis with kainic acid and N-methyl-D-aspartate. J. Neurosci. 3: 1701-1711.

Thomson, A. M., and D. Lodge (1985) Selective blockade of an ex- citatory synapse in rat cerebral cortex by the sigma opiate cyclazocine: An intracellular in vitro study. Neurosci. Lett. 54: 21-26.

Wallén, P., S. Grillner, J. L. Feldman, and S. Bergelt (1985) Dorsal and ventral myotome motoneurones and their input during fictive locomotion in lamprey. J. Neurosci. 5: 654-661.

Watkins, J. C., and R. H. Evans (1981) Excitatory amino acid transmitters. Annu. Rev. Pharmacol. Toxicol. 21: 165-206. 